\title{
Data Revisions of Aggregate Hours Worked: Implications for the Europe-U.S. Hours Gap
}

\author{
Alexander Bick, Bettina Brüggemann, and Nicola Fuchs-Schündeln
}

In this article, we document that the Organisation for Economic Co-operation and Development (OECD) and the Conference Board's Total Economy Database (TED) have substantially revised their measures of hours worked over time. Relying on the data used by Rogerson (2006) and Ohanian et al. (2008), we find that, for 2003, hours worked per person in Europe is 18 percent lower than hours worked in the United States. Using the 2016 releases of the same data for 2003 yields a gap that is 40 percent smaller-that is, only 11 percent lower. Using labor force survey data, which are less subject to data revisions, we find a Europe-U.S. hours gap of -19 percent. (JEL C82, E24, J21, J22)

Federal Reserve Bank of St. Louis Review, First Quarter 2019, 101(1), pp. 45-56.

https://doi.org/10.20955/r.101.45-56

\section{INTRODUCTION}

Rogerson (2006) documents large differences in hours worked per person among Organisation for Economic Co-operation and Development (OECD) countries for the early 2000s. Specifically, based on data from the OECD and the Total Economy Database (TED), he finds that hours worked per person in the 16 European countries in his sample are substantially lower than those in the United States. In this article, we show that using the 2016 releases of the same data yields a gap between European and U.S. hours worked per person that is about 40 percent smaller than the gap he found. Because the data used by Rogerson (2006) were not published along with his study, we replicate his results using the data from his companion article with Ohanian and Raffo (Ohanian et al., 2008), available online in the Journal of Monetary Economics. The implied Europe-U.S. hours worked per person gap is -17.6 percent for 2003, the latest available year in their data set. Using the 2016 release of the same data yields a gap for 2003 of only -11.0 percent, thus 37.5 percent lower. We document that these drastically

\footnotetext{
Alexander Bick is a visiting scholar at the Federal Reserve Bank of St. Louis and an associate professor in the Department of Economics at the W.P. Carey School of Business, Arizona State University; Bettina Brüggemann is an assistant professor in the Department of Economics at McMaster University; and Nicola Fuchs-Schündeln is a professor of Macroeconomics and Development at Goethe University Frankfurt and a research fellow at the Centre for Economic Policy Research. The authors thank Valerie Ramey for helpful comments and the encouragement to write this article. The authors gratefully acknowledge financial support from the Cluster of Excellence "The Formation of Normative Orders" at Goethe University and the European Research Council under Starting Grant No. 262116.

(c) 2019, Federal Reserve Bank of St. Louis. The views expressed in this article are those of the author(s) and do not necessarily reflect the views of the Federal Reserve System, the Board of Governors, or the regional Federal Reserve Banks. Articles may be reprinted, reproduced, published, distributed, displayed, and transmitted in their entirety if copyright notice, author name(s), and full citation are included. Abstracts, synopses, and other derivative works may be made only with prior written permission of the Federal Reserve Bank of St. Louis.
} 
different results originate mainly from revisions of the hours worked per employed series used in the calculation of hours worked per person. Next to Rogerson (2006) and Ohanian et al. (2008), the implied Europe-U.S. hours worked per person gaps in Prescott (2004) and McDaniel (2011) are also subject to such revisions. $\frac{1}{}$ Using labor force survey data, which are less subject to data revisions, we find a Europe-U.S. hours gap of -19 percent. We further show that the different formulas used to calculate hours worked per person in these articles have only negligible effects on the estimated Europe-U.S. hours worked per person gap.

\section{LITERATURE OVERVIEW}

In this section, we provide a brief overview of how hours worked per person have been calculated in the literature and which data sources have been used. The upper panel of Table $1 \mathrm{~A}$ lists the main articles that explain differences in hours worked between a large set of European countries and the United States. Column 2 states the formula used in each article to calculate hours worked per person, while column 3 lists the respective time period covered. The first four articles calculate hours worked per person by multiplying average hours worked per employed with various measures of the civilian employment-to-population ratio. The first three articles calculate the latter as civilian employment without an age limit divided by the population aged 15 to 64, with Prescott (2004) also including non-civilian employment. Ragan (2013) restricts the employment-to-population ratio to the age group 25 to 64 . Henceforth, we use the term employment rate interchangeably for these employment-to-population ratios. McDaniel (2011) differs from these articles by directly dividing total hours worked by the population aged 15 to 64. We exclude Alesina et al. (2005) and Faggio and Nickell (2007) from Table 1, because their measure of hours worked per employed are based on data published in a special section of the OECD's Economic Outlook 2004. These data are not part of the OECD's general database and are as such not subject to their usual maintenance and revisions. Moreover, their measure of hours worked per employed was obtained from labor force surveys (LFS), which are usually not subject to larger revisions.

In Bick et al. (2018), we construct internationally comparable hours-worked measures for the United States and 18 European countries on a more disaggregate level-for example, by gender and education - using national LFS. Such detailed measures of hours worked have not been available so far. The article discusses in detail the strategy of how we achieve comparability of hours worked across countries and over time, a task far from trivial. 2 We also contrast the aggregate hours implied by the LFS data with those from the National Income and Product Accounts (NIPA). For both types of data sources, we use conceptually the same formula (see the lower panel of Table 1A). Here, we intentionally use the product formulation-that is, hours worked per employed times the respective employment-to-population ratio-because it highlights that in our calculation employment cancels out, as in McDaniel (2011). For the first four studies listed in Table 1A this is not necessarily the case. We do not know whether the denominator in average hours worked per employed referred to total or civilian employment in earlier data releases. Thus, it may or may not be equal to the numerator in the respective employment-to-population ratio. We elaborate on this further below. 


\section{Table 1}

\begin{tabular}{|c|c|c|}
\hline \multicolumn{3}{|c|}{ A: Hours Worked per Person Formulas and Time Period Covered } \\
\hline Reference & Hours worked per person & Period \\
\hline \multirow{2}{*}{ Prescott (2004) } & Avg. hours worked per employed $\times$ Civilian + Non-civilian employment & \multirow{2}{*}{ Avg. $1970-73$ and $1993-96$} \\
\hline & Population 15-64 & \\
\hline \multirow{2}{*}{ Rogerson (2006) } & \multirow{2}{*}{ Avg. hours worked per employed $\times \frac{\text { Civilian employment }}{\text { Population 15-64 }}$} & \multirow{2}{*}{2003} \\
\hline & & \\
\hline \multirow{2}{*}{ Ohanian et al. (2008) } & \multirow{2}{*}{ Avg. hours worked per employed $\times \frac{\text { Civilian employment }}{\text { Population 15-64 }}$} & \multirow{2}{*}{ 1956-2004 } \\
\hline & & \\
\hline \multirow{2}{*}{ Ragan (2013) } & \multirow{2}{*}{ Avg. hours worked per employed $\times \frac{\text { Civilian employment 25-64 }}{\text { Population 15-64 }}$} & \multirow{2}{*}{ Avg. 1998-2003 } \\
\hline & & \\
\hline \multirow{2}{*}{ McDaniel (2011) } & Total hours & \multirow{2}{*}{$1960-2004$} \\
\hline & Population 15-64 & \\
\hline
\end{tabular}

Bick et al. (2018)

\begin{tabular}{|c|c|c|c|}
\hline \multirow{2}{*}{ NIPA } & Total hours & Total employment & \multirow{2}{*}{$1983-2015$} \\
\hline & Total employment & Population 15-64 & \\
\hline \multirow{2}{*}{ LFS } & Civilian hours & Civilian employment & \multirow{2}{*}{$1983-2015$} \\
\hline & Civilian employment & Civilian population 15-64 & \\
\hline
\end{tabular}

\section{B: Data Sources}

\begin{tabular}{|c|c|c|c|}
\hline Reference & Hours & Employment & Population \\
\hline Prescott (2004) & \multicolumn{3}{|c|}{ OECD Labour Database - Labour Force Statistics } \\
\hline Rogerson (2006) & TED & \multicolumn{2}{|c|}{ OECD Labour Market Database Statistics } \\
\hline Ohanian et al. (2008) & TED [2008] & \multicolumn{2}{|c|}{$\begin{array}{l}\text { Various issues of the OECD's Economic Outlook } \\
\text { and Main Economic Indicators }\end{array}$} \\
\hline Ragan (2013) & \multicolumn{3}{|c|}{ OECD Labour Market Statistics } \\
\hline McDaniel (2011) & TED [2007] & & OECD \\
\hline \multicolumn{4}{|l|}{ Bick et al. (2018) } \\
\hline NIPA (OECD) & \multicolumn{2}{|c|}{ OECD NA Database* [2016] } & OECD ALFS ${ }^{\dagger}[2016]$ \\
\hline NIPA (TED) & \multicolumn{2}{|c|}{ TED [2016] } & $\mathrm{OECD} \mathrm{ALFS}^{\dagger}[2016]$ \\
\hline LFS & \multicolumn{3}{|c|}{ National Labor Force Surveys [2016] } \\
\hline
\end{tabular}

SOURCE: *OECD National Accounts Database; ${ }^{\dagger}$ OECD Labour Database, Labour Force Statistics, and Annual Labour Force Statistics. 
The upper panel of Table 1B states the data sources exactly as specified in each of the five articles. Numbers in parentheses refer to the year of publication of each article, whereas numbers in brackets refer to the year of the data release if provided by the authors in the respective article. Employment and population figures are always taken from the OECD, while average hours worked per employed are taken from either the OECD or different TED releases, which in earlier years was maintained jointly by the Conference Board and the Groningen Growth and Development Centre.

The lower panel of Table 1B states the data sources used in Bick et al. (2018). We report here two NIPA measures, which only differ in their source for hours worked per employed. We take total hours and total employment from either the OECD's National Accounts Database, downloaded in March 2016, or the May 2016 TED release. We denote both measures by NIPA because for most years and countries both data sources report exactly the same numbers. We normalize both NIPA measures with the population aged 15 to 64 from the OECD's Annual Labour Force Statistics, downloaded in August 2016. We calculate our LFS measure of hours worked per person using only information from the national LFS for hours worked,

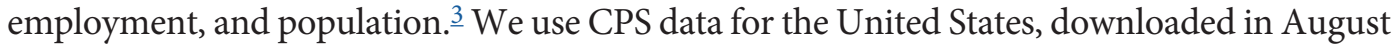
2016 from the NBER's website, and use the European Union Labor Force Survey as provided to us by Eurostat in 2014. The LFS also undergo revisions, but these are minor revisions concentrated on certain quarters and countries and for only a few variables at a time. ${ }^{4}$

Both the OECD and TED also report average hours worked per employed as a separate variable, which is used in the articles by Prescott (2004), Rogerson (2006), Ohanian et al. (2008), and Ragan (2013). The TED's average hours worked per employed is simply total hours worked divided by total employment from the TED. The OECD's Average Annual Hours Worked per Employed series can be found in the OECD's Labour Database under the section Labour Force Statistics. Similar to the TED estimate, this estimate is equal to total hours worked divided by total employment from the OECD's National Account Database, although there are small differences for a few countries in some years. We are not entirely sure whether in earlier releases of the data, hours worked per employed were similarly calculated as total hours divided by total employment; in the September 2006 TED release, hours worked per employed are defined as "total hours divided by persons engaged."

In our analysis of the effects of data revisions, we draw data for civilian employment from the OECD's Labour Database under the section Labour Force Statistics. Two data series are available: one under the category LFS by sex and age (LFSsa) and one under the category Annual Labour Force Statistics (ALFS). As we show further below, the differences between LFSsa and ALFS employment are small for most countries. The difference with total employment from NIPA data is, however, non-negligible for both series. Hence, at least for the 2016 data release, employment does not cancel out in the formulas used by the first four articles in Table 1A. We come to this conclusion because average hours worked per employed, directly available from the OECD and TED, are largely based on total hours and total employment, as discussed above. If we add non-civilian employment, which is available for a subset of countries in the ALFS, to civilian employment from the LFSsa or ALFS, we do not arrive at total employment from NIPA, such that for the formula used by Prescott (2004), employment also does not cancel out. 


\section{EVALUATING DIFFERENCES IN LABOR SUPPLY MEASURES ORIGINATING FROM DIFFERENT DATA RELEASES}

In this section, we evaluate the role of revisions between different data releases for the measurement of hours worked based on OECD and TED data. Because the data used by Rogerson (2006) for 2003 were not published along with his study, we conduct our comparison based on the data used in his companion article with Ohanian and Raffo (Ohanian et al., 2008). These are available online in the Journal of Monetary Economics. Note that Ohanian et al. (2008) focus only on the cross-country comparisons of trends. Therefore, in principle, our study relates to the article by Rogerson (2006), but we use the data from Ohanian et al. (2008) for the analysis. .5 We restrict our attention to the United States and the set of 15 European countries that are part of the Ohanian et al. (2008) sample and the Bick et al. (2018) sample. $\underline{6}$ We report all results for 2003, the latest year available in the Ohanian et al. (2008) dataset with information for all variables. In our conclusion, we briefly discuss the remaining articles listed in Table 1.

Rogerson (2006) and Ohanian et al. (2008) calculate hours worked per person as the product of hours worked per employed from the TED and the employment rate from the OECD. In a first step, we investigate the effect of different data releases on each separate component. Then, we look at how hours worked per person are affected by the different releases and how important each margin is in shaping such potential differences. We want to stress again that in all these comparisons, the numbers are reported for 2003 but are based on data released in different years.

\subsection{Employment Rates and Hours Worked per Employed}

The first column of Table 2 lists the employment rate $\left(e_{O R R}\right)$ using the Ohanian et al. (2008) data. The next two columns show the percentage differences between the employment rates based on civilian employment from the OECD's ALFS and LFSsa, respectively, and the Ohanian, Raffo, and Rogerson (ORR) employment rate. In each case the employment rate is given by civilian employment divided by the population aged 15 to 64 for 2003, as available in August 2016 from the OECD's website. For example, in Spain, the country with the largest differences, the ALFS employment rate is 3.9 percent (2.3 percentage points) higher than the ORR employment rate, whereas the LFSsa employment rate is 4.4 percent (2.6 percentage points) higher than the ORR employment rate. On average, in European countries the absolute differences between the ORR employment rate and the ALFS and LFSsa employment rates are 1.2 percent and 1.9 percent, respectively, and in the United States the absolute differences for the OECD series are both 0.4 percent. While the differences with the ORR employment rate are already not that large on average, the differences between the ALFS and LFSsa employment rates are even smaller, as can be indirectly inferred from comparing columns 2 and 3 in the table. (Switzerland is the only exception.)

The fourth column of Table 2 lists the average hours worked per employed using the Ohanian et al. (2008) data, which come from the 2008 TED release. While for civilian employment we have access to only the 2016 OECD data release, we have several TED data releases 
Bick, Brüggemann, Fuchs-Schündeln

\section{Table 2}

\section{Employment Rate and Average Hours Worked per Employed Differences for 2003}

\begin{tabular}{|c|c|c|c|c|c|c|c|c|}
\hline \multirow[b]{2}{*}{ Country } & \multicolumn{3}{|c|}{ Employment rate } & \multicolumn{5}{|c|}{ Average hours worked per employed } \\
\hline & $e_{O R R}$ & $\Delta_{\text {ALFS, } 2016 \text { Rel. }}$ & $\Delta_{\text {LFSsa, } 2016 \text { Rel. }}$ & $H_{O R R}^{E}$ & $\Delta_{2006 \text { Rel. }}$ & $\Delta_{2011 \text { Rel. }}$ & $\Delta_{2013 \text { Rel. }}$ & $\Delta_{2016 \text { Rel. }}$ \\
\hline Austria & 68.7 & -0.4 & -0.1 & $1,498.5$ & 1.1 & 15.3 & 18.5 & 19.0 \\
\hline Belgium & 58.6 & 2.1 & 2.1 & $1,618.9$ & 0.0 & -2.7 & -2.7 & -2.5 \\
\hline Denmark & 74.6 & 1.4 & 1.5 & $1,519.0$ & 2.1 & 2.2 & 2.2 & -2.5 \\
\hline France & 62.5 & 3.3 & 0.8 & $1,428.6$ & 0.2 & 7.3 & 3.1 & 3.9 \\
\hline Germany & 63.2 & 2.4 & 3.0 & $1,441.4$ & -0.2 & -0.2 & -0.4 & -1.2 \\
\hline Greece & 59.7 & -1.1 & -1.4 & $1,929.0$ & 0.0 & 9.0 & 9.0 & 8.4 \\
\hline Ireland & 66.0 & 0.5 & 0.9 & $1,652.7$ & 0.0 & 14.5 & 14.2 & 14.2 \\
\hline Italy & 56.3 & 0.9 & 2.4 & $1,608.7$ & 0.0 & 13.5 & 13.5 & 12.9 \\
\hline Netherlands & 73.2 & 1.1 & -2.0 & $1,352.1$ & 4.1 & 3.6 & 3.6 & 5.5 \\
\hline Norway & 75.5 & 0.0 & 0.8 & 1,336.3 & 0.1 & 4.6 & 4.8 & 5.1 \\
\hline Portugal & 71.2 & 1.4 & 2.0 & $1,702.2$ & 0.0 & 13.6 & 13.6 & 10.8 \\
\hline Sweden & 72.8 & 0.0 & 2.0 & $1,553.4$ & 0.6 & 1.8 & 1.8 & 1.8 \\
\hline Spain & 57.8 & 3.9 & 4.4 & $1,798.5$ & 0.0 & -5.2 & -4.4 & -2.4 \\
\hline Switzerland & 83.9 & -0.2 & -5.0 & $1,537.0$ & 0.0 & 6.7 & 5.8 & 5.9 \\
\hline United Kingdom & 72.3 & 0.0 & 0.4 & $1,623.9$ & 0.0 & 3.3 & 3.3 & 2.8 \\
\hline Mean absolute & 67.7 & 1.2 & 1.9 & $1,573.3$ & 0.6 & 6.9 & 6.7 & 6.6 \\
\hline United States & 70.9 & 0.4 & 0.4 & $1,817.1$ & -1.2 & -5.9 & -5.9 & -1.9 \\
\hline
\end{tabular}

NOTE: The percentage deviations of the ALFS and LFSsa employment rates (each taken from the 2016 data release) from the Ohanian, Raffo, and Rogerson (ORR) employment rate for 2003 are $\Delta_{\text {ALFS, } 2016 \text { Rel. }}$ and $\Delta_{\text {LFSSa, } 2016 \text { Rel, }}$, respectively. The employment rate is measured as civilian employment divided by the population aged 15 to 64 . The percentage deviation of average hours worked per employed from the TED release in year $Y$ from the ORR average hours worked per employed (2008 TED release) for 2003 is $\Delta_{Y \text { Rel. }}$.

SOURCE: OECD National Accounts Database; OECD Labour Database, Labour Force Statistics, and Annual Labour Force Statistics; Ohanian et al. (2008).

available. Columns 5 to 8 show the percentage differences between average hours worked per employed from these different TED releases, each time compared with the 2008 release. While the 2011 TED release and all subsequent releases are available on the Conference Board's website, the September 2006 release was shared with us by Cara McDaniel. For many countries there are no differences at all between the 2006 TED release and 2008 TED release-that is, the data available from Ohanian et al. (2008). The mean absolute difference is only 0.6 percent, and the largest difference is present for the Netherlands: Average hours worked per employed in the 2006 release exceed those from the 2008 release by 4.1 percent. This changes drastically when we compare the 2011 release with the 2008 release. More than half of the countries have (absolute) differences that are larger than 4.1 percent (the largest difference between the 2006 and 2008 releases). Austria, Ireland, Italy, and Portugal display double-digit percentage differences. The mean absolute average amounts to 6.9 percent for the European countries, with 
Table 3

Hours Worked per Person Differences for 2003

Percent of deviation explained by

\begin{tabular}{lrrrrr} 
Country & $H_{\text {ORR }}$ & $H_{2016 \text { Rel. }}$ & $\Delta_{2016 \text { Rel. }}$ & $\Delta_{e}$ & $\Delta_{H^{E}}$ \\
\hline Austria & $1,028.8$ & $1,220.0$ & 18.6 & 18.6 & 102.1 \\
\hline Belgium & 948.2 & 943.7 & -0.5 & -0.5 & 544.4 \\
\hline Denmark & $1,133.6$ & $1,121.2$ & -1.1 & -1.1 & 228.0 \\
\hline France & 892.5 & 957.8 & 7.3 & 7.3 & 55.1 \\
\hline Germany & 910.7 & 921.6 & 1.2 & 1.2 & -98.6 \\
\hline Greece & $1,152.3$ & $1,235.5$ & 7.2 & 7.2 & 115.4 \\
\hline Ireland & $1,090.8$ & $1,251.4$ & 14.7 & 14.7 & 96.7 \\
\hline Italy & 905.4 & $1,031.3$ & 13.9 & 13.9 & 93.4 \\
\hline Netherlands & 989.9 & $1,056.0$ & 6.7 & 6.7 & 83.4 \\
\hline Norway & $1,008.9$ & $1,060.2$ & 5.1 & 5.1 & 100.0 \\
\hline Portugal & $1,211.2$ & $1,360.6$ & 12.3 & 12.3 & 89.0 \\
\hline Sweden & $1,131.0$ & $1,151.5$ & 1.8 & 1.8 & 100.2 \\
\hline Spain & $1,039.0$ & $1,054.0$ & 1.4 & 1.4 & -170.0 \\
\hline Switzerland & $1,289.7$ & $1,363.0$ & 5.7 & 5.7 & 102.9 \\
\hline United Kingdom & $1,174.0$ & $1,206.4$ & 2.8 & 2.8 & 101.1 \\
\hline Mean & $1,060.4$ & $1,129.0$ & 6.5 & 6.5 & -1.5 \\
\hline United States & $1,287.5$ & $1,268.2$ & -1.5 & & 126.7 \\
\hline
\end{tabular}

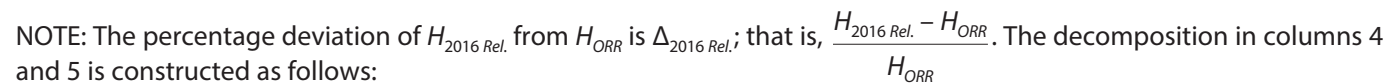

$$
\begin{aligned}
& H_{2016 \text { Rel. }}-H_{\text {ORR }}=e_{\text {ALFS }} \times H_{2016 ~ R e l .}^{E}-e_{\text {ORR }} \times H_{O R R}^{E} \\
& H_{2016 \text { Rel. }}-H_{\text {ORR }}=e_{\text {ALFS }}\left(H_{2016 \text { Rel. }}^{E}-H_{O R R}^{E}\right)+H_{O R R}^{E}\left(e_{\text {ALFS }}-e_{\text {ORR }}\right) \\
& 1=\frac{e_{\text {ALFS }}\left(H_{2016 \text { Rel. }}^{E}-H_{\text {ORR }}^{E}\right)}{\underbrace{H_{2016 \text { Rel }}-H_{\text {ORR }}}_{=A_{H E}(\text { Rol. } 5)}}+\frac{H_{\text {ORR }}^{E}\left(e_{\text {ALFS }}-e_{\text {ORR }}\right)}{\underbrace{H_{2016 \text { Rel }}-H_{\text {ORR }}}_{=A_{e}(\text { Col. } 4)}}
\end{aligned}
$$

where $\Delta_{e}$ is the fraction of $H_{2016 \text { Rel. }}-H_{\text {ORR }}$ accounted for by differences between the ALFS and ORR employment rates, and $\Delta_{H^{E}}$ is the fraction of $H_{2016 \text { Rel. }}-H_{O R R}$ accounted for by differences between hours worked per employed from the 2016 and 2008 TED releases. Note that this decomposition is not unique. We weight the hours worked per employed difference by $e_{A L F S}$ and the employment rate difference by $H_{O R R}^{E}$. Using as weights $e_{O R R}$ and $H_{2016 \text { Rel. }}^{E}$ leaves the results virtually unchanged.

SOURCE: OECD National Accounts Database; OECD Labour Database, Labour Force Statistics, and Annual Labour Force Statistics; Ohanian et al. (2008).

most countries having a positive difference. In contrast, the average hours worked per employed for the United States from the 2011 release are 5.9 percent lower than those from the 2008 release. The large differences with the 2008 release persist for the European countries in the 2013 and 2016 releases, even though there are some substantial changes between the more recent releases (e.g., for France between 2011 and 2013 and for Denmark between 2013 and 
2016). For the United States, the 2016 release is much closer to the 2008 release than are the 2011 and 2013 releases. These results already make clear that data revisions affect the measurement of hours worked per employed substantially but the measurement of the employment rate only slightly. We will back this up more formally further below.

\subsection{Hours Worked per Person}

We now use the formula in Rogerson (2006) and Ohanian et al. (2008) to calculate hours worked per person for 2003. We compare the hours worked per person directly obtained from Ohanian et al. (2008), $H_{O R R}$, with those from the 2016 data releases, $H_{2016 \text { Rel. }}$. Specifically, we calculate the latter by multiplying average hours worked per employed from the May 2016 TED release with the ALFS employment rate (downloaded in August 2016 from the OECD's website)..

As a reminder, we report the hours for 2003 based on data released in different years. The first column of Table 3 shows $H_{O R R}$, the second column shows $H_{2016 \text { Rel. }}$, and the third column shows the percentage deviations of $H_{2016 \text { Rel. }}$ from $H_{O R R}$. For the European countries, hours worked per person are, on average, 6.5 percent larger in the 2016 data than those in the Ohanian et al. (2008) data, while for the United States, hours worked per person are 1.5 percent lower in the 2016 data than those in the Ohanian et al. (2008) data. The last two columns show what fraction of the hours worked per person difference is accounted for by differences in both the employment rate and hours worked per employed. Equation (1) in Table 3 states the formula for these calculations.

For Belgium, Denmark, Germany, Sweden, and Spain, this decomposition is less informative because the (weighted) differences in hours worked per employed and employment rates are divided by the small difference in hours worked per person (less than 2 percent in absolute value). We therefore do not show the mean across all European countries. For France for 2003, the difference in hours worked per employed accounts for 55 percent of the difference in hours worked per person-between the ORR data based on the 2008 TED release and the 2016 TED release. For the other countries, the differences in hours worked per employed account for at least 83 percent of the difference in hours worked per person.

\section{THE EUROPE-U.S. HOURS WORKED PER PERSON GAP: THE EFFECT OF DIFFERENT DATA RELEASES AND FORMULAS}

In this section, we analyze the role of using different data releases and different formulas for the measurement of the Europe-U.S. hours gap for 2003. In addition, we contrast those findings with the Europe-U.S. hours gap constructed with the LFS by Bick et al. (2018).

The first two columns in Table 4 show the hours worked per person gap relative to the United States for $H_{O R R}$ (using the original Ohanian et al., 2008, data; i.e., column 1 in Table 3) and for $H_{2016 \text { Rel. }}$ (using the 2016 release of the same Ohanian et al., 2008, data; i.e., column 2 in Table 3) for 2003. Constructing hours worked per person as in Rogerson (2006) and Ohanian et al. (2008) but using the 2016 release yields a much smaller gap of -11.0 percent between Europe and the United States, compared with -17.6 percent based on the original 
Table 4

Hours Worked per Person Relative to the United States for 2003

\begin{tabular}{lrrrrr} 
Country & ORR & 2016 Rel. & NIPA (TED) & NIPA (OECD) & LFS \\
\hline Austria & -20.1 & -3.8 & -4.9 & -3.5 & -17.0 \\
\hline Belgium & -26.4 & -25.6 & -25.3 & -24.3 & -30.5 \\
\hline Denmark & -12.0 & -11.6 & -12.2 & -10.9 & -14.5 \\
\hline France & -30.7 & -24.5 & -23.2 & -22.1 & -27.2 \\
\hline Germany & -29.3 & -27.3 & -21.4 & -20.2 & -25.9 \\
\hline Greece & -10.5 & -2.6 & -1.4 & 0.0 & -15.3 \\
\hline Ireland & -15.3 & -1.3 & -2.1 & -0.7 & -17.0 \\
\hline Italy & -29.7 & -18.7 & -11.3 & -10.0 & -31.9 \\
\hline Netherlands & -23.1 & -16.7 & -15.5 & -14.3 & -23.0 \\
\hline Norway & -21.6 & -16.4 & -15.6 & -14.4 & -19.5 \\
\hline Portugal & -5.9 & 7.3 & 6.3 & 7.9 & -8.2 \\
\hline Sweden & -12.2 & -9.2 & -7.9 & -6.6 & -17.1 \\
\hline Spain & -19.3 & -16.9 & -14.1 & -12.8 & -23.8 \\
\hline Switzerland & 0.2 & 7.5 & 5.7 & 7.2 & -4.1 \\
\hline United Kingdom & -8.8 & -4.9 & -5.8 & -4.5 & -14.6 \\
\hline Mean & -17.6 & -11.0 & -9.9 & -8.6 & -19.3
\end{tabular}

SOURCE: OECD National Accounts Database; OECD Labour Database, Labour Force Statistics, and Annual Labour Force Statistics; Ohanian et al. (2008).

ORR data. As shown in Table 3, this is mostly driven by major revisions of the hours worked per employed TED data between the 2008 release and later releases. Column 3 in turn shows hours worked per person using the NIPA formula (McDaniel, 2011, and Bick et al., 2018) and the TED data. This implies that employment refers to total employment in hours worked per employed and the employment rate. Hence, the only difference between columns 2 and 3 is that the employment figures cancel out in column 3 but not in column 2 . This has only a small effect on the Europe-U.S. hours gap of, on average, 1.1 percentage points. Germany and Italy stand out with large differences. Column 4 shows our calculations if we use the OECD hours rather than the TED hours. The Europe-U.S. hours gap differs only by 1.3 percentage points, which is mostly driven by a higher estimate in the TED revisions of hours worked per person in the United States. As the last column of Table 4 shows, the Europe-U.S. hours gap in the original Ohanian et al. (2008) data set is quite similar to the one we find in LFS data.

In Bick et al. (2018), we provide a detailed discussion of the potential forces behind the different NIPA and LFS estimates using the 2016 OECD release. LFS and NIPA data differ conceptually along two dimensions. First, LFS data cover only civilian, non-institutionalized residents aged 15 and older, while the NIPA does not impose these restrictions, to ensure that the labor inputs are consistent with the measurement of gross domestic output. Second, the 
NIPA estimates are usually constructed in country-specific ways from multiple data sources (administrative data, social security data, employer surveys, labor force surveys, census data, etc.). We show suggestive evidence that the differences in population coverage are not very important. For the United States, Abraham et al. (2013) investigate which features of the underlying data sources drive the differences between NIPA and LFS employment estimates, and Eldridge et al. (2004) and Frazis and Stewart (2010) do the same for hours worked per employed. While the details are specific to the United States, these articles highlight advantages and disadvantages of household survey data used in the LFS estimates vs. administrative data used in the NIPA estimates. The combination of multiple data sources might deliver more accurate estimates of employment and hours worked for a given country. The downside is that crosscountry comparability suffers, despite the efforts to harmonize measurement through the System of National Accounts (see Fleck, 2009). In fact, the OECD remarks on its website that "The [hours worked] data are intended for comparisons of trends over time; they are unsuitable for comparisons of the level of average annual hours of work for a given year, because of differences in their sources" and recommends using employment rates based on national LFS for cross-country comparisons: "National Labour Force Surveys are the best way to capture unemployment and employment according to the ILO guidelines that define the criteria for a person to be considered as unemployed or employed... While data from LFS make international comparisons easier compared to a mixture of survey and registration data, there are some differences across countries in coverage, survey timing, etc., that may affect international comparisons of labour market outcomes." the main differences in the cross-country comparability of the LFS, namely the survey timing. 9

If one is interested in hours worked for different demographic subgroups, the LFS is the only option. For aggregate applications only, researchers should be aware of the differences between the LFS and NIPA data on the one hand and the potential for major revisions of the latter over time on the other.

\section{CONCLUSION}

In this article, we compare the effect of different formulas used in the macro literature for calculating hours worked per person and the effect of different data releases on the hours estimates. In doing so, we focus on the data provided by Ohanian et al. (2008). We show that the TED revisions of hours worked per employed have a large impact on the conclusions drawn. Put differently, if Rogerson (2006) would have had the 2016 data release, he would have found a close to 40 percent lower Europe-U.S. hours gap (-11.0 percent) than what he found with the data available in the mid-2000s (-17.6 percent). Using labor force survey data, which are less subject to data revisions, we find a Europe-U.S. hours gap of -19 percent.

Since McDaniel (2011) uses the 2007 TED data release, the facts in her article are affected by revisions in a similar way as those in Rogerson (2006) and Ohanian et al. (2008). Ragan (2013), in turn, uses the OECD average hours worked per employed and is thus not affected by any TED data revisions. However, the OECD average hours worked per employed also underwent revisions. For the (smaller) set of European countries in Ragan's data, the average 
absolute difference in hours worked per employed between the release she used and the 2016 release of the same data is 3.8 percent (see Table A.2 in the online Appendix, https://alexbick.weebly.com/uploads/1/0/1/3/101306056/bbf note onlineappendix.pdf). This is a smaller difference than that between the TED releases, but it is still substantial. Moreover, the OECD revisions are not due to a change in guidelines in the System of National Accounts (SNA 93 vs. SNA 2008). The OECD provides NIPA employment and NIPA hours under both guidelines on its website. For the 2016 release, the differences are small for most countries, with the exception of the Netherlands, Portugal, and Spain (see Table A.3 in the online Appendix). Finally, like Ragan (2013), Prescott (2004) uses hours worked per employed directly from the OECD. Using the same set of countries (the United States, France, Italy, Germany, and the United Kingdom) and time period (1993-96) as Prescott does, we qualitatively reconfirm our findings from the comparison with Rogerson (2006) and Ohanian et al. (2008) for 2003; for a detailed discussion, see the online Appendix. Relying on the OECD and TED 2016 data releases yields a smaller Europe-U.S. hours gap than when using data from the same sources available to researchers in the early 2000 s.

Finally, as we show in online Appendix B, the data revisions also affect the measurement of time trends in hours worked per person. While the secular decrease in European hours worked per person between 1956 and 2003 is present in both the Ohanian et al. (2008) data and the 2016 release of the same data, the decline in the sample of European countries is 27 percent (6.1 percentage points) smaller in the 2016 release. In turn, hours worked per person in the United States increased by 3.6 percent using the 2016 data release and by only 0.4 percent using the Ohanian et al. (2008) data.

\section{NOTES}

1 Ragan (2013) is an exception. While the underlying data she used were subject to non-negligible revisions on the country level, the average Europe-U.S. hours gap is nearly left unchanged.

2 Hours worked per employed and weeks worked in the OECD Economic Outlook 2004, which is used by Alesina et al. (2005) and Faggio and Nickell (2007), are constructed in a similar way as those in Bick et al. (2018). Both approaches are based on national LFS and use external data sources for annual leave and public holidays to estimate weeks worked per year. The key difference lies in the treatment of weekly hours lost (relative to usual hours worked) for reasons other than annual leave and public holidays. In our approach, these reduce weekly hours worked per employed but do not affect weeks worked per year, whereas in the OECD Economic Outlook 2004 it is the other way around.

$\underline{3}$ To ensure the comparability across countries and over time, we need to make an adjustment using external data sources for public holidays and annual leave, to overcome differences in the sets of weeks sampled across countries and over time. For details, we refer the reader to Bick et al. (2018).

4 The first draft of this article was written in August 2016. Since then, both the OECD and TED have updated their data. There were no major revisions in those releases relative to the data available in August 2016.

$\underline{5}$ Using the data from Ohanian et al. (2008) for 2003 yields the same results as presented in Table 1 in Rogerson (2006).

6 We drop Finland from the Ohanian et al. (2008) sample and the Czech Republic, Hungary, and Poland from the Bick et al. (2018) sample.

7 We use the ALFS employment rate rather than the LFSsa employment rate because the former shows a smaller mean absolute difference with the employment rate used by Ohanian et al. (2008). 


\section{Bick, Brüggemann, Fuchs-Schündeln}

8 Both quotes we retrieved from the OECD's website on August 29, 2018: http://stats.oecd.org/Index.aspx?DataSetCode=ANHRS and http://www.oecd.org/els/emp/basicstatisticalconceptsemploymentunemploymentandactivityinlabourforcesurveys.htm.

9 Other reasons impeding the comparability across time and countries of the LFS, which we cannot adjust for, are the revision of population figures used for population adjustment on the basis of new population censuses, as well as changes in the sampling design, and content or order of the questionnaire. For details, see http://ec.europa.eu/eurostat/statistics-explained/index.php/EU labour force survey (retrieved on March 10, 2017).

\section{REFERENCES}

Abraham, K.G.; Haltiwanger, J.; Sandusky, K. and Spletzer, J.R. “Exploring Differences in Employment Between Household and Establishment Data." Journal of Labor Economics, 2013, 31(2), pp. S129-72; https://doi.org/10.1086/669062.

Alesina, A.; Glaeser, E. and Sacerdote, B. "Work and Leisure in the United States and Europe: Why So Different?" NBER Macroeconomics Annual, 2005, 20, pp. 1-64; https://doi.org/10.1086/ma.20.3585411.

Bick, A.; Brüggemann, B. and Fuchs-Schündeln, N. "Hours Worked in Europe and the U.S.: New Data, New Answers." Scandinavian Journal of Economics, 2018, forthcoming.

Eldridge, L.P.; Manser, M.E. and Otto, P.F. "Alternative Measures of Supervisory Employee Hours and Productivity Growth." Monthly Labor Review, April 2004, pp. 9-28; https://www.bls.gov/opub/mlr/2004/04/art2full.pdf.

Faggio, G. and Nickell, S. "Patterns of Work Across the OECD." Economic Journal, 2007, 117, pp. F416-40; https://doi.org/10.1111/j.1468-0297.2007.02062.x.

Fleck, S.E. "International Comparisons of Hours Worked: An Assessment of Statistics." Monthly Labor Review, May 2009, 132(5), pp. 3-31; https://www.bls.gov/opub/mlr/2009/05/art1full.pdf.

Frazis, H. and Stewart, J. "Why Do BLS Hours Series Tell Different Stories About Trends in Hours Worked?" BLS Working Paper 433, Bureau of Labor Statistics, 2010; https://www.bls.gov/osmr/pdf/ec100010.pdf.

McDaniel, C. "Forces Shaping Hours Worked in the OECD, 1960-2004." American Economic Journal: Macroeconomics, 2011, 3, pp. 27-52; https://doi.org/10.1257/mac.3.4.27.

Ohanian, L.; Raffo, A. and Rogerson, R. "Long-Term Changes in Labor Supply and Taxes: Evidence from OECD Countries, 1956-2004." Journal of Monetary Economics, 2008, 55, pp. 1353-62; https://doi.org/10.1016/j.jmoneco.2008.09.012.

Prescott, E.C. "Why Do Americans Work So Much More Than Europeans?" Federal Reserve Bank of Minneapolis Quarterly Review, 2004, 28, pp. 2-13; https://www.minneapolisfed.org/research/qr/qr2811.pdf.

Ragan, K. "Taxes, Transfers and Time Use: Fiscal Policy in a Household Production Model." American Economic Journal: Macroeconomics, 2013, 5(1), pp. 168-92; https://doi.org/10.1257/mac.5.1.168.

Rogerson, R. "Understanding Differences in Hours Worked." Review of Economic Dynamics, 2006, 9, pp. 365-409; https://doi.org/10.1016/j.red.2006.05.002. 